\title{
Effects of Albedo in Urban Planning - Special Reference to Building Roofs
}

\author{
Akshey Bhargava* and Swati Bhargava \\ Department of Civil Engineering, Global Institute of Engineering and Technology, India \\ *Corresponding author: Akshey Bhargava, Department of Civil Engineering Global Institute of Engineering and Technology, Hyderabad, India, 23 \\ Pursuing master's in 'Sustainable Environmental Design (SED); AA School of Architecture, London, UK
}

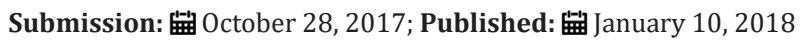

\begin{abstract}
Surface albedo is defined as the ratio of irradiance reflected to the irradiance received by a surface wherein the proportion reflected is not only determined by properties of the surface itself, but also by the spectral and angular distribution of solar radiation reaching the Earth's surface. Albedo is an important concept in climatology, astronomy, and environmental management including urban planning. Any albedo in visible light falls within a range of about 0.9 for fresh snow to about 0.04 for charcoal, one of the darkest substances [1]. One of the land surface properties that has been changed due to urbanization is albedo which is ranging from 0 (complete absorption) to 1 (complete reflection). Roofs and pavements, which constitute about 20-25\% and 29-44\% respectively of typical urban surfaces, generally have lower albedos than their surrounding areas. An effort has been made by the authors in the present paper to discuss the effect of albedo in urban planning with emphasis on building roofs.
\end{abstract}

Keywords: Albedo; Effects; Urban planning

\section{Introduction}

Usually in many urban areas, pavements and roofs constitute over $60 \%$ of urban surfaces (roof $20-25 \%$, pavements about $40 \%$ ). The albedo of roof and the pavement can be increased by about 0.25 and 0.10 , respectively, resulting in a net albedo increase for urban areas of about 0.1.Many studies have demonstrated building cooling-energy savings in excess of $20 \%$ by raising roof reflectivity from $10-20 \%$ to about $60 \%$. Increasing albedo of urban surfaces can reduce the summer time urban temperature and improve the urban air quality. Increasing the urban albedo has the added benefit of reflecting more of the incoming global solar radiation and countering the effect of global warming [2]. As per simple global model, the change in air temperature in lowest $1.8 \mathrm{~km}$ of the atmosphere is estimated at $0.01 \mathrm{~K}$. Modelers predict a warming of about $3 \mathrm{~K}$ in the next 60 years $(0.05 \mathrm{~K} /$ year $)$. Change of 0.1 in urban albedo will result in $0.01 \mathrm{~K}$ global cooling, a delay of $\sim 0.2$ years in global warming. This 0.2 years delay in global warming is equivalent to $10 \mathrm{Gt}$ reductions in $\mathrm{Co}_{2}$ emissions [3].

It has been studied and demonstrated scientifically that increased urban albedo leads to reduction in use of cooling energy along with cooling urban areas and improving urban air quality. Akbari \& Konopacki [1] have reviewed the solar reflectance of typical roofing materials used on residential and commercial buildings in many U.S. regions. A solar-reflective roof is typically light in color and absorbs less sunlight than a conventional dark-colored roof [4]. Less absorbed sun light means a lower surface temperature, directly reducing heat gain from the roof and air-conditioning demand. Cool-colored fiber glass asphalt shingles with a solar reflectance of 0.25 . Some reflective tiles and metal roofing products with greater than $50 \%$ reflectivity are also available. Conversely, highly reflective materials for the low-slope commercial sector are on the market [5]. White acrylic, elastomeric and cementatious coatings, as well as white thermoplastic membranes, can now be applied to built-up roofs to achieve an aged solar-reflectance of 0.6. The albedo of typical standard roofing materials ranges from $0.10-0.25$; one can conservatively assume that the average albedo of existing roofs does not exceed 0.20 . The albedo of these surfaces can be increased to about 0.55 to 0.60 .

\section{Building Energy Demand}

Surface albedo changes due to urbanization have resulted into higher air temperature in the urban areas than their rural surroundings which commonly known as the "urban heat island effect". Elevated temperature in the summertime results in an increase in cooling demand for buildings and excess GHG emissions from producing the energy required to fulfill the needs. Akbari et al. [6] reported that for the major metropolitan areas in the U.S, peak electricity load would increase by $1.5-2 \%$ for every $1^{\circ} \mathrm{F}$ increase in ambient temperature [6]. There has been growing concern in mitigating the UHI effect by using suitable reflective materials for roofs and pavements. Reflective materials can reduce cooling loads of buildings in summer whereas increase heating loads in winter 
[7]. The latter is known as the "heating penalty" of high albedo. The relative magnitudes of cooling saving and heating penalties depend on a combination of multiple factors, including location, climate conditions, building types, the source of energy used for heating and cooling, etc. Akbari et al. [6] found the largest net savings in the hottest and sunniest cities and that the savings decreased as the climate got cooler, the resultant net savings were positive even in colder climates for most building types. Levinson \& Akbari [6] predicted that reflective roofs always reduced the annual cooling load more than it increased the annual heating load

The impact of reflective pavements on building energy consumption is more complicated as it is affected by the interaction between pavements and buildings, as well as the energy exchanges in surface-atmosphere interactions. Yaghoobian et al. (2010) found a cooling load saving of $17 \%$ in buildings due to a reduction in shortwave radiation transfer from the ground to nearby buildings by using low-albedo ground surfaces, rather than reflective pavements [8]. In a later study, they found that increasing pavement albedo from 0.1 to 0.5 near a four-story office building in Phoenix would increase annual cooling loads up to $11 \%(33.1 \mathrm{kWh} / \mathrm{m} 2)$, while annual heating load was not sensitive to such a modification [9]. These results indicate the potential of increasing cooling loads in adjacent buildings by absorbing more radiation from reflective pavements.

\section{Conclusion}

Albedo is an important parameter in the overall design of urban planning [10]. Significant research needs to be taken up for different locations under different climatic conditions for different cities in regard to saving of energy vis-à-vis increasing albedo [11]. More and effective roof and pavement surfaces need to be researched and manufactures for enhancing the magnitude of albedo. However, in Indian conditions higher albedo would result in net saving of energy.

\section{References}

1. Akbari H, Konopacki S (2005) Calculating energy saving potentials of heat-island reduction strategies. Energy Policy 33(6): 721-756.

2. Akbari H, Rose LS, Taha H (2003) Analyzing the land cover of an urban environment using high-resolution orthophotos Landscape and Urban Planning 63(1): 1-14.

3. Akbari H, Rose LS (2001) Characterizing the fabric of the urban environment: A case study of Metropolitan Chicago, Illinois. Lawrence Berkeley National Laboratory pp. 1-60.

4. Akbarin H, and Rose LS (2001) "Characterizing the Fabric of the Urban Environment: A Case Study of Salt Lake City, Utah." Lawrence Berkeley National Laboratory pp. 1-52.

5. Akbari H, Pomerantz M, Taha V (2001) Cool surfaces and Shade Trees to Reduce Energy Use and Improve Air Quality in Urban Areas. Solar Energy 70(3): 295-310.

6. Betts R (2001) Biophysical impacts of land use on present-day climate: near surface temperature and radiative forcing. Atmospheric Science Letters 1: 1-13.

7. Chase TN, Pielke RA, Kittel TGF, Nemani RR, Running SW, et al. (2000) Simulated impacts of historical land cover changes on global climate innorthern winter. Climate Dynamics 16(2-3): 93-105.

8. Harte J (1988) Consider a Spherical Cow. University Science Books, Berkeley, CA, USA, pp. 166-174.

9. Hansen J, Sato M, Lacis A, Ruedy R, Tegen I, et al. (1998) Climate forcings in the industrial era. Proc Natl Acad Sci 95(22): 12753-12758.

10. Hansen J, Sato M, Ruedy R (1997) Radiative forcing and climate response. Journal forcing \& Atmospheric Chemistry 102(D6): 6831-6864.

11. Jacobson MZ (2002) Control of fossil-fuel particulate black carbon and organic matter, possibly the most effective method of slowing global warming. Journal of Geophysical Research 107(D19): ACH 16-1-ACH 16-22. 